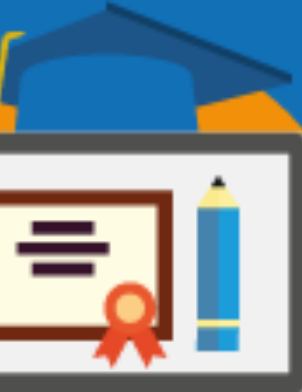

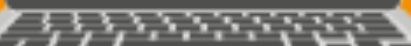

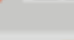

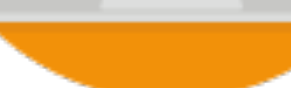

\title{
A ATUAÇÃO DOCENTE NA EDUCAÇÃO A DISTÂNCIA A PARTIR DO CENSO DA EDUCAÇÃO SUPERIOR, DO INSTITUTO NACIONAL DE ESTUDOS E PESQUISAS EDUCACIONAIS ANÍSIO TEIXEIRA - INEP (2018)
}

Juliane Aparecida Ribeiro Diniz Universidade Federal de Goiás - UFG Faculdade Alfredo Nasser - UNIFAN

Murilo José de Souza Pires Instituto de Pesquisa Econômica Aplicada - IPEA murilo.pires@ipea.gov.br

Eixo 04: Trabalho docente e Processos Didáticos na EaD

Resumo: Este trabalho de pesquisa busca apresentar breve caracterização da atuação docente na Educação a Distância brasileira a partir dos microdados do Censo da Educação Superior, do INEP, ano 2018. Para tanto, os caminhos metodológicos adotados foram pesquisa documental, em que o Censo foi considerado documento, bem como pesquisa analítica descritiva, cujo fim é o detalhamento de características de uma população ou de dados coletados. Os resultados encontrados indicam que a maioria dos docentes que se dedicam ao ensino superior a distância estão presentes em universidades privadas, com títulos de mestres e doutores, atuando em regime de trabalho integral sem dedicação exclusiva e parcial e dedicando-se mais à graduação do que à pós-graduação e muito pouco às atividades de pesquisa e extensão.

Palavras-chave: Educação a Distância. Atuação docente. Censo do Ensino Superior.

\section{Introdução}

A Educação a Distância (EaD) no Brasil tem ganhado espaço como modalidade de ensino desde a promulgação da Lei de Diretrizes e Bases da Educação Nacional, n. 9394, de 20 de dezembro de 1996, a qual estabeleceu, em seu artigo 80, que o governo federal incentivaria o desenvolvimento do ensino a distância em todos os níveis e modalidades de ensino, como meio de democratizar o ensino e ampliar o acesso à educação em todo o território nacional.

Contudo, percebe-se que a $\mathrm{EaD}$ se cristaliza no Brasil antes mesmo de sua regulamentação formal e que várias iniciativas de implantação dessa modalidade remetem-se 
ao início do século XX, com cursos por correspondência, depois por meio de rádio e televisão, em seguida transmissão de cursos e teleconferências via satélite e, atualmente, com a utilização de internet e ambientes virtuais, o que permitiu que o ensino a distância fosse expandido e ganhasse perceptibilidade.

Assim sendo, cabe ressaltar que cada uma dessas iniciativas se dispôs de algum instrumento de mediação do ensino e aprendizagem, mas sempre teve o educador como organizador deste processo. Dessa forma, entende-se que o professor teve e tem papel fundamental na Educação a Distância, pois a ele compete a função de organizar estratégias de construção dos saberes dentro dessa modalidade, como ainda de mediar e criar situações didáticas. Sendo assim, compreende-se, ainda, que as alterações nas perspectivas da EaD, também transformou a performance desse profissional e, de tal modo, faz-se necessário entender como este atua na época presente.

Dessa forma, esse trabalho tem por objetivo apresentar algumas características empíricas da atuação docente na Educação a Distância brasileira no ano de 2018. Para tanto, tais evidências encontram-se sistematizadas e classificadas na base de microdados do Instituto Nacional de Estudos e Pesquisas Educacionais Anísio Teixeira - INEP, as quais tem como fito subsidiar a descrição das variáveis que caracterizam a população dos docentes, dos cursos, das Instituições de Ensino Superior - IES e dos discentes que compõem o sistema de ensino superior brasileiro.

Para tanto, o percurso metodológico adotado foi a pesquisa documental, em que o Censo da Educação Superior do INEP foi considerado um documento, bem como a pesquisa analítica descritiva, isto é, decompôs-se a categoria 'atuação do docente' em suas partes constituintes e a reconstruiu, de forma descritiva, mediada por evidências teóricas, cujo fim foi o detalhamento das características que moldam o comportamento da atuação dos docentes brasileiros nas instituições de ensino superior públicas e privadas, no ano de 2018. Sendo assim, tais dados foram analisados e organizados em tabelas com utilização do programa de estatística Stata (Statistic/Data Analysis, versão 14.2), para cruzamento das informações relevantes acerca da atuação dos docentes do ensino superior a distância.

\section{SEMINÁRIO DE EDUCAÇÃO A DISTÂNCIA}




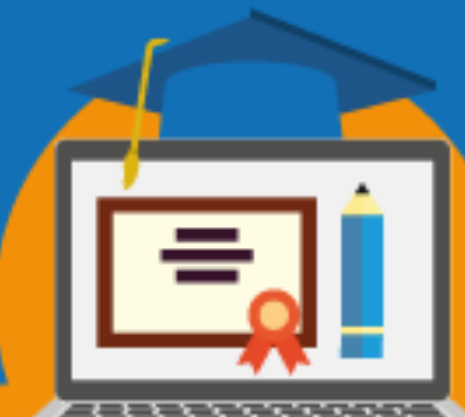

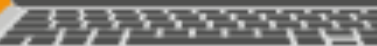

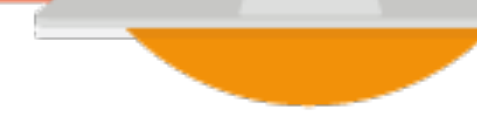

A motivação para o desenvolvimento desta investigação se fundamenta em várias dimensões. Entre elas, destaca-se o levantamento e a discussão de dados quantitativos que exemplificam as evidências gerais apontadas pela literatura sobre o tema, mas que não quantificam os elementos centrais que expressam a uniformidade e a regularidade do fenômeno da educação a distância no Brasil. Por isso, esse trabalho justifica-se também no sentido de conhecer um pouco mais empiricamente como se objetiva a atuação do docente da educação superior a distância no Brasil, no ano de 2018.

Por fim, este trabalho encontra-se dividido em três seções. A primeira tem por objetivo explicitar alguns fatos relevantes do processo de institucionalização da EaD no Brasil. A seguinte expõe os dados sobre a atuação do docente da Educação a Distância brasileira a partir dos microdados do Censo da Educação Superior, ano 2018. E, por fim, seguem-se as considerações finais.

\section{Fatos estilizados' sobre o processo de institucionalização da Educação a Distância no} Brasil:

Neste estudo, compreende-se a Educação a Distância “como modalidade educacional na qual a mediação didático-pedagógica nos processos de ensino e aprendizagem ocorre com a utilização de meios e tecnologias de informação e comunicação, com estudantes e professores desenvolvendo atividades educacionais em lugares ou tempos diversos" (BRASIL, 2005).

Dessa forma, entende-se que a trajetória da $\mathrm{EaD}$ é um processo que perpassa cinco gerações, em sua organização, as quais são: a primeira marcada pelo texto e pelas aprendizagens via correspondências; a segunda com utilização do rádio e da televisão para propagação do conhecimento; a terceira geração caracterizada pela criação das Universidades Abertas; a quarta fundamentada na interação de um grupo em tempo real a distância, em cursos transmitidos por

\footnotetext{
${ }^{1}$ Entende-se como fato estilizado uma aproximação teórica de um fenômeno observado empiricamente. 0 termo "fato estilizado" é comum nas Ciências Sociais, principalmente na Economia, e foi utilizado primeiramente por Nicholas Kaldor, em 1957, com fins de resumir as propriedades estatísticas do crescimento econômico de longo prazo.
} 


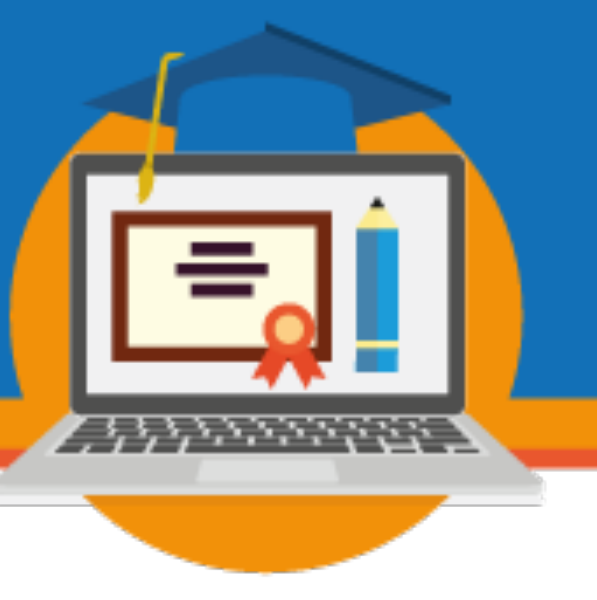

áudios e videoconferências por meio de telefone, satélite, cabo e redes de computadores; e, por fim, a quinta geração, envolvendo o ensino e aprendizado on-line em classes e universidades virtuais baseadas em tecnologias de Internet (MOORE E KEARSLEY, 2013).

Lima (2013) ressalta que no Brasil, em específico, a implantação da Educação a Distância ocorreu também por gerações, contudo em sequências diferentes. Há indícios de cursos por correspondência no país desde o ano de 1904, por meio de rádios no ano de 1923 e por intermédio de programas televisivos desde 1970. Todavia, os cursos transmitidos por satélite e redes de computadores datam-se do final da década de 1970 e início dos anos 1980, com cursos a distância em várias áreas do conhecimento, e o primeiro curso de graduação a distância, Pedagogia, com utilização de ferramentas de tecnologia digital, pela Universidade Federal do Mato Grosso - UFMT, principiou sua oferta em 1992. E, em 2006, a Universidade Aberta do Brasil - UAB é estabelecida pelo Decreto 5.800, com objetivo de "ampliar e interiorizar a oferta de cursos e programas de educação superior, por meio da educação à distância", reduzindo as desigualdades na oferta de ensino universitário e desenvolvendo um amplo sistema nacional de educação superior à distância².

Então, entende-se que a terceira geração explicitada por Moore e Kearsley (2013), ocorreu, no Brasil, após o estabelecimento da quarta e quinta fase de desenvolvimento da Educação a Distância, ou seja, de forma tardia em relação a outros países (LIMA, 2013). Mas, é relevante ressaltar que, a criação da UAB se configurou um avanço na oferta de cursos superiores a distância, bem como representou uma possibilidade de democratização, expansão, interiorização e progresso do ensino universitário público, gratuito e de qualidade socialmente referenciada.

No âmbito privado percebeu-se, também, um crescimento acelerado da oferta de cursos superiores a distância a partir de 1996, principalmente pelo ‘como' os empresários passaram a considerá-la e concebê-la: uma possibilidade de expansão dos negócios empresariais com baixo custo de produção, com maximização dos lucros e com abrangência territorial para além das regiões metropolitanas, conforme Ruas (2015).

\footnotetext{
2 Informações retiradas do site: http://www.capes.gov.br/uab/o-que-e-uab.
} 


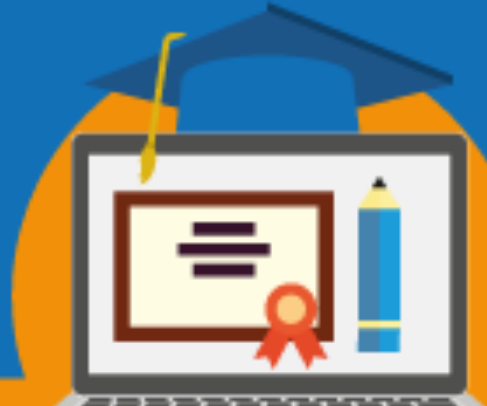

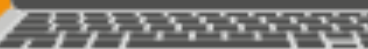

Isso foi possibilitado pela diversificação de instituições de ensino superior (Universidade, Centro Universitário e Faculdade), pela diferenciação dos cursos (bacharelado, licenciatura, tecnológico, sequencial, aperfeiçoamento e extensão) e pela distinção na modalidade de oferta: presencial, semipresencial ou a distância, propostas pela LDB 9394 (BRASIL, 1996).

Desse modo, nesse processo de 'democratização do ensino superior', de aumento de vagas e de matrículas, de ampliação de acesso e de diversificação de modalidades, é que se percebe a crescente oferta de cursos de Educação à Distância, no setor público e privado, em que as tecnologias de informações tornam-se instrumentos de mediação do processo de ensino e aprendizagem.

Acerca desse cenário, há autores como Cavalcanti (2009), Silva (2010), Mill (2006, 2012) indicando que o trabalho docente sofreu diversas modificações, acompanhando esta perspectiva de mudanças da modalidade de ensino. Por isso, esse trabalho justifica-se no sentido de conhecer a atuação do docente da educação superior a distância no Brasil, compreendendo as ações e a formação desse profissional, principalmente nos dados do último Censo da Educação Superior (INEP, 2018).

\section{Atuação docente na Educação a Distância no ano de 2018}

No ano de 2018 foram aplicados 373.025 questionários aos docentes que atuam nas instituições de ensino superior brasileiras, segundo os microdados do INEP. Contudo, o universo desse estudo foi delimitado pela variável-foco 'atuação em EaD', a qual agrega o somatório de 360.432 docentes. Destes, que responderam tal questionamento, tem-se um total de 18.180 atuantes na educação a distância, representando, assim, um percentual de 5,04\%.O restante deles, que perfaz quase 95\% (342.252), trabalham no ensino superior presencial. Já no caso dos discentes, os microdados do Censo do Ensino Superior (INEP, 2018) apresentam um total bastante significativo: 3.054.005 alunos.

\section{SEMINÁRIO DE EDUCAÇÃO A DISTÂNCIA}


Tabela 1 - Categoria administrativa ${ }^{3}$

\begin{tabular}{|l|c|c|c|}
\hline \multicolumn{1}{|c|}{ Categoria Administrativa } & Pública & Privada & Total \\
\hline Presencial & 155.524 & 186.728 & 342.252 \\
\hline EaD & 5.766 & 12.414 & 18.180 \\
\hline Total & $\mathbf{1 6 1 . 2 9 0}$ & $\mathbf{1 9 9 . 1 4 2}$ & $\mathbf{3 6 0 . 4 3 2}$ \\
\hline
\end{tabular}

Fonte: Elaboração própria a partir dos microdados do Censo da Educação Superior 2018.

No universo total do ensino superior, ao se tratar a categoria 'docentes que atuam na EaD', observa-se que os 5,04\% estão distribuídos da seguinte forma: 3,4\% nas IES privadas e 1,6\% nas IES públicas. Por outro lado, quando se analisa especificamente os docentes que atuam na educação a distância, certifica-se que quase $70 \%$ deles estão em instituições privadas e o restante estão em públicas. Em linhas gerais, pode-se aferir a partir desses dados que há uma predominância de docentes do ensino superior a distância nas IES privadas.

\section{Tabela 2 - Organização acadêmica}

\begin{tabular}{|l|r|r|r|r|r|r|}
\hline $\begin{array}{c}\text { Organizaçã } \\
\text { o acadêmica }\end{array}$ & Universidade & $\begin{array}{c}\text { Centro } \\
\text { universitário }\end{array}$ & \multicolumn{1}{|c|}{$\begin{array}{c}\text { Faculdade } \\
\text { s }\end{array}$} & $\begin{array}{c}\text { Instituto } \\
\text { Federal de } \\
\text { Educação, } \\
\text { Ciência e } \\
\text { Tecnologia - IF }\end{array}$ & $\begin{array}{c}\text { Centro } \\
\text { Federal de } \\
\text { Educação } \\
\text { Tecnológica } \\
\text { - CEFET }\end{array}$ & Total \\
\hline Presencial & 182.169 & 43.640 & 94.396 & 20.734 & 1.313 & 342.252 \\
\hline EaD & 11.343 & 4.490 & 1.868 & 443 & 36 & 18.180 \\
\hline Total & $\mathbf{1 9 3 . 5 1 2}$ & $\mathbf{4 8 . 1 3 0}$ & $\mathbf{9 6 . 2 6 4}$ & $\mathbf{2 1 . 1 7 7}$ & $\mathbf{1 . 3 4 9}$ & $\mathbf{3 6 0 . 4 3 2}$ \\
\hline
\end{tabular}

Fonte: Elaboração própria a partir dos microdados do Censo da Educação Superior 2018.

Ao se verificar o conjunto dos docentes do ensino superior brasileiro (360.432), no ano de 2018, nota-se que 3,15\% dos que atuam no ensino a distância está em Universidades, 1,25\%

${ }^{3}$ As instituições de ensino superior públicas compreendem as mantidas pelo Poder Público Federal, Estadual e Municipal. As instituições privadas referem-se às categorias privadas com fins lucrativos, privadas sem fins lucrativos não beneficente e beneficente e a especial (BRASIL, Ministério das relações exteriores. Denominações das Instituições de Ensino Superior (IES). Disponível em: http://www.dce.mre.gov.br/nomenclatura cursos.html. Acessado em 05/01/2020).

\section{SEMINÁRIO DE EDUCAÇÃO A DISTÂNCIA}




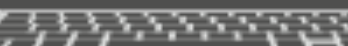

em Centros Universitários, 0,52\% em Faculdades e 0,12\% em Institutos Federais de Educação, Ciência e Tecnologia. Por outro lado, ao se observar a totalidade dos docentes que trabalham especificamente com a EaD (18.180), 62,39\% destes encontram-se em Universidades, 24,70\% em Centros Universitários, 10,28\% em Faculdades e 2,64\% em IF e CEFET. Logo, entende-se que, em sua maioria, os docentes da $\mathrm{EaD}$ estão em Universidades privadas.

\section{Tabela 3 - Escolaridade}

\begin{tabular}{|l|r|r|r|r|r|r|}
\hline Escolaridade & Sem graduação & Graduação & Especialista & Mestrado & Doutorado & \multicolumn{1}{c|}{ Total } \\
\hline Presencial & 15 & 3.493 & 58.271 & 132.680 & 147.793 & 342.252 \\
\hline EaD & 0 & 46 & 2.188 & 7.890 & 8.056 & 18.180 \\
\hline Total & $\mathbf{1 5}$ & $\mathbf{3 . 5 3 9}$ & $\mathbf{6 0 . 4 5 9}$ & $\mathbf{1 4 0 . 5 7 0}$ & $\mathbf{1 5 5 . 8 4 9}$ & $\mathbf{3 6 0 . 4 3 2}$ \\
\hline
\end{tabular}

Fonte: Elaboração própria a partir dos microdados do Censo da Educação Superior 2018.

Percebe-se, pelos dados explicitados na tabela 3, que dos docentes atuantes no ensino superior brasileiro a distância, mais de $87 \%$ possuem titulação strictu sensu, dos quais $44,31 \%$ são doutores e 43,40\% são mestres. Portanto, compreende-se que existe uma prevalência de mestres e de doutores na Educação a Distância no Brasil.

\section{Tabela 4 - Regime de trabalho}

\begin{tabular}{|l|r|r|r|r|r|}
\hline $\begin{array}{c}\text { Regime de } \\
\text { trabalho }\end{array}$ & $\begin{array}{c}\text { Tempo integral com } \\
\text { dedicação exclusiva }\end{array}$ & $\begin{array}{l}\text { Tempo integral sem } \\
\text { dedicação exclusiva }\end{array}$ & Parcial & Horista & Total \\
\hline Presencial & 110.706 & 74.197 & 95.879 & 61.470 & 342.252 \\
\hline EaD & 4.409 & 5.595 & 5.447 & 2.729 & 18.180 \\
\hline Total & $\mathbf{1 5 . 1 1 5}$ & $\mathbf{7 9 . 7 9 2}$ & $\mathbf{1 0 1 . 3 2 6}$ & $\mathbf{6 4 . 1 9 9}$ & $\mathbf{3 6 0 . 4 3 2}$ \\
\hline
\end{tabular}

Fonte: Elaboração própria a partir dos microdados do Censo da Educação Superior 2018.

\footnotetext{
${ }^{4}$ Entende-se por regime de tempo integral o docente contratado com 40 horas semanais de trabalho na mesma instituição, reservado o tempo de pelo menos 20 horas semanais a estudo, pesquisa, trabalho de extensão, gestão, planejamento, avaliação e orientação de estudantes, com ou sem dedicação exclusiva. 0 de tempo parcial é o docente contratado com 12 ou mais horas semanais de trabalho na mesma instituição, reservado pelo menos $25 \%$ do tempo para estudo, planejamento, avaliação e orientação de estudantes. E o horista é o docente contratado pela instituição apenas para ministrar aulas, independente da carga horária contratada, ou que não se enquadre em outros regimes de trabalho acima definidos. (BRASIL, Ministério das relações exteriores. Denominações das Instituições de Ensino Superior (IES). Disponível em: http://www.dce.mre.gov.br/nomenclatura cursos.html. Acessado em 05/01/2020).
}

\section{SEMINÁRIO DE EDUCAÇÃO A DISTÂNCIA}


Pode-se afirmar que ao analisar o universo total de professores do ensino superior brasileiro, 1,55\% dos docentes que atuam na educação a distância apresenta um regime de trabalho de tempo integral sem dedicação exclusiva, ao passo que $1,51 \%$ apresenta um regime de trabalho parcial, 1,22\% de tempo integral com dedicação exclusiva e $0,76 \%$ de horista. Isso significa, no caso específico dos docentes atuantes na $\mathrm{EaD}$, que o regime de tempo integral sem dedicação exclusiva apresenta $30,78 \%$, o regime de trabalho parcial representa quase $30 \%$, o de tempo integral com dedicação exclusiva compõe-se de pouco mais de $24 \%$ e, por fim, o regime horista indica um percentual de $15 \%$. Observa-se, portanto, que pouco mais de $60 \%$ dos docentes, que trabalham no ensino superior a distância no Brasil, encontram-se em regime de tempo integral sem dedicação exclusiva e parcial.

\section{Tabela 5 - Atuação em pesquisa}

\begin{tabular}{|l|r|r|r|}
\hline \multicolumn{1}{|c|}{ Atuação em Pesquisa } & Não & \multicolumn{1}{c|}{ Sim } & \multicolumn{1}{c|}{ Total } \\
\hline Presencial & 235.701 & 106.551 & 342.252 \\
\hline EaD & 12.767 & 5.413 & 18.180 \\
\hline Total & $\mathbf{2 4 8 . 4 6 8}$ & $\mathbf{1 1 1 . 9 6 4}$ & $\mathbf{3 6 0 . 4 3 2}$ \\
\hline
\end{tabular}

Fonte: Elaboração própria a partir dos microdados do Censo da Educação Superior 2018.

De acordo com a tabela 5, observa-se que do total dos docentes de ensino superior no Brasil, somente $1,5 \%$ efetivamente atua em pesquisas e trabalha com a Educação a Distância de modo simultâneo. Já no caso dos 18.180 docentes que atuam especificamente na EaD, verifica-se que $29,77 \%$ destes dedicam-se a pesquisas e que $70,23 \%$ não o fazem. Assim sendo, constata-se que há poucos docentes que atuam no ensino a distância e realizam pesquisas concomitantemente.

\section{Tabela 6 - Bolsas de pesquisa}

\begin{tabular}{|l|r|r|r|}
\hline \multicolumn{1}{|c|}{ Bolsas de Pesquisa } & Não & \multicolumn{1}{c|}{ Sim } & \multicolumn{1}{c|}{ Total } \\
\hline Presencial & 90.827 & 15.724 & 106.551 \\
\hline EaD & 4.656 & 757 & 5.413 \\
\hline Total & $\mathbf{9 5 . 4 8 3}$ & $\mathbf{1 6 . 4 8 1}$ & $\mathbf{1 1 1 . 9 6 4}$ \\
\hline
\end{tabular}


Fonte: Elaboração própria a partir dos microdados do Censo da Educação Superior 2018.

Ao se analisar os dados referentes ao recebimento de bolsas de pesquisas pelos professores do ensino superior brasileiro, é importante ressaltar que somente 111.964 responderam esse questionamento, o que representa apenas $31,07 \%$ do total destes. Se forem observadas as informações no âmbito do ensino superior a distância, tem-se a constatação de que 757 docentes atuam na $\mathrm{EaD}$ e possuem bolsas de pesquisa, ou seja, isso retrata que $0,68 \%$ dos educadores recebem bolsas de pesquisas e atuam no ensino a distância de forma conjunta.

Portanto, percebe-se que a maioria dos docentes dedicados às atividades de docência na Educação a Distância não possuem bolsas de estudo e pesquisa.

Tabela 7 - Atuação em atividades de extensão

\begin{tabular}{|l|r|r|r|}
\hline \multicolumn{1}{|c|}{ Atuação em extensão } & Não & Sim & \multicolumn{1}{c|}{ Total } \\
\hline Presencial & 244.695 & 97.557 & 342.252 \\
\hline EaD & 12.545 & 5.635 & 18.180 \\
\hline Total & $\mathbf{2 5 7 . 2 4 0}$ & $\mathbf{1 0 3 . 1 9 2}$ & $\mathbf{3 6 0 . 4 3 2}$ \\
\hline
\end{tabular}

Fonte: Elaboração própria a partir dos microdados do Censo da Educação Superior 2018.

Em conformidade com os dados destacados na tabela 7, nota-se que apenas $1,56 \%$ do total dos professores de ensino superior brasileiro atuam em educação a distância e em atividades de extensão conjuntamente. Por outro lado, no caso dos docentes que trabalham especificamente com o ensino superior a distância, observa-se que 31\% destes atuam em extensão. Sumariamente, pode-se aferir que há predomínio de poucos docentes que se dedicam ao ensino e à extensão na educação a distância em nível superior associadamente.

\section{Tabela 8 - Atuação em pós-graduação EaD}

\begin{tabular}{|l|r|r|r|}
\hline \multicolumn{1}{|c|}{ Atuação em Pós EaD } & \multicolumn{2}{c|}{ Não } & \multicolumn{2}{c|}{ Total } \\
\hline Presencial & 341.406 & 846 & 342.252 \\
\hline EaD & 18.079 & 101 & 18.180 \\
\hline Total & $\mathbf{3 5 9 . 4 8 5}$ & $\mathbf{9 4 7}$ & $\mathbf{3 6 0 . 4 3 2}$ \\
\hline
\end{tabular}

Fonte: Elaboração própria a partir dos microdados do Censo da Educação Superior 2018. 
Constata-se, pelos dados apresentados na tabela 8 , que apenas $0,56 \%$ dos docentes atuantes na EaD brasileira dedicam-se, ainda, a atividades de ensino em cursos de pósgraduação strictu sensu a distância. Isso representa no universo total dos docentes do ensino superior no Brasil uma porcentagem de $0,03 \%$ destes que trabalham com educação a distância e pós-graduação strictu sensu a distância. Deste modo, atenta-se uma primazia de docentes que se dedicam ao ensino em cursos de graduação vis-à-vis a mestrados e doutorados a distância.

\section{Tabela 9 - Relação entre alunos por docentes na EaD}

\begin{tabular}{|l|r|r|r|}
\hline \multicolumn{1}{|c|}{ Descrição } & \multicolumn{1}{c|}{ Pública } & \multicolumn{1}{c|}{ Privada } & \multicolumn{1}{c|}{ Total } \\
\hline Alunos & 237.288 & 2.816 .717 & 3.054 .005 \\
\hline Docente & 5.766 & 12.414 & 18.180 \\
\hline Alunos/Docentes & $\mathbf{4 1 , 1 5}$ & $\mathbf{2 2 6 , 9 0}$ & $\mathbf{1 6 7 , 9 9}$ \\
\hline
\end{tabular}

Fonte: Elaboração própria a partir dos microdados do Censo da Educação Superior 2018.

A tabela 9 explicita a relação entre alunos por docentes nas instituições públicas e privada no ensino superior a distância. Compreende-se, então, que nas IES públicas tem-se uma média de 41,15 alunos por professor, enquanto que nas instituições privadas observa-se uma média de 226,90 alunos por professor da Educação a Distância, ou seja, a razão entre alunos por docentes nas IES privadas responde por mais do que o quíntuplo daquela encontrada para as instituições públicas.

\section{Considerações Finais}

O presente estudo teve por objetivo geral apresentar uma breve caracterização da atuação docente na Educação a Distância brasileira, a partir dos microdados do Censo da Educação Superior, do Instituto Nacional de Estudos e Pesquisas Educacionais Anísio Teixeira - INEP, ano 2018.

Dessa forma, foi possível observar que a maioria dos docentes dessa modalidade de ensino encontra-se na organização acadêmica universidade, de caráter privado, sob o regime de trabalho integral sem dedicação exclusiva (40h/aula) e parcial, ou seja, contratado para atuar com 12 ou mais horas semanais de trabalho na mesma instituição de ensino superior.

\section{SEMINÁRIO DE EDUCAÇÃO A DISTÂNCIA}




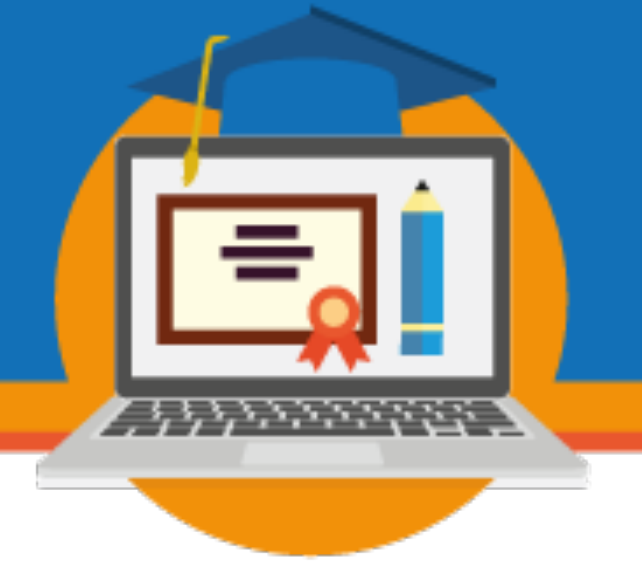

Com relação à titulação acadêmica pode-se afirmar que a maioria dos docentes da EaD tem formação strictu sensu, isto é, possuem mestrados e doutorados e atuam em sua grande maioria em cursos de graduação em detrimentos dos cursos de pós-graduação a distância. Contudo, apenas $29,77 \%$ destes realizam pesquisas, $31 \%$ devotam-se a atividades de extensão e $0,68 \%$ possuem bolsas de estudo e pesquisa das agências de fomento do país.

Tais dados demonstram uma necessidade de maior dedicação dos professores do ensino superior a distância nas atividades que compõem a tríade desse nível educacional: ensino, pesquisa e extensão, pois fica explícito que a docência é a atividade de predominância na atuação destes professores. Tanto que se percebe, no cruzamento dos dados do número de docentes e número de alunos da educação a distância brasileira, de acordo com as categorias administrativas, que nas instituições privadas, aqueles atendem um número bem maior destes, em atividades maioritariamente de docência.

\section{Referências}

BRASIL. Decreto 5622. Regulamenta o art. 80 da Lei ${ }^{\circ}$ 9.394, de 20 de dezembro de 1996, que estabelece as diretrizes e bases da educação nacional. Brasília: Ministério da Educação, 10 de dezembro de 2005.

BRASIL. Instituto Nacional de Estudos e Pesquisas Educacionais Anísio Teixeira (INEP). Censo da Educação Superior 2018. Brasília, 19 de setembro de 2019.

BRASIL. Lei de Diretrizes e Bases da Educação Nacional. Lei n 9394. Brasília, MEC/SEF, de 20 de dezembro de 1996.

CAVALCANTI, A. S. C. O barateamento da educação: uma abordagem sobre a tutoria no contexto da resolução FNDE $n^{\circ}$ 26/2009. In: VI CONGRESSO BRASILEIRO DE ENSINO SUPERIOR A DISTÂNCIA, 2009, São Luís. Anais... São Luiz: UEMANET, 2009.

LIMA, Daniela da Costa Britto Pereira. Políticas públicas de EaD no ensino superior: uma análise a partir das capacidades do Estado. Rio de Janeiro, 2013. 285 f. Tese (doutorado) Universidade Federal do Rio de Janeiro, Instituto de Economia, Programa de Pós-Graduação em Políticas Públicas, Estratégias e Desenvolvimento, 2013. 


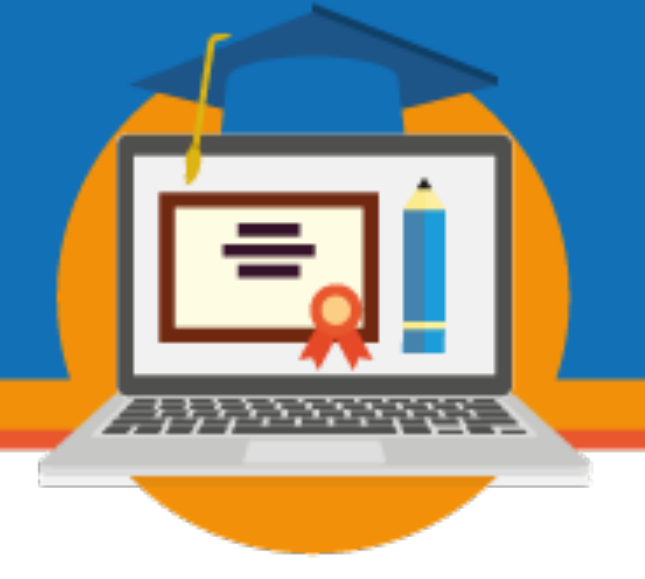

MILL, Daniel. Educação a distância e trabalho docente virtual. 2006. 322f. Tese (Doutorado em Educação). FAE/UFMG, Belo Horizonte, 2006.

MILL, Daniel. Docência virtual: uma visão crítica. Campinas: Papirus, 2012.

MOORE, M; KEARSLEY, G. Educação a distância: sistemas de aprendizagem on-line. 3.ed. São Paulo: Cengage Learning, 2013.

RUAS, Claudia Mara Stapani. Grandes oligopólios da educação superior e gestão do grupo Anhanguera educacional. Tese de Doutorado. Programa de Pós-graduação em Educação. Brasília: UCDB, 2015.

SILVA, Sandra Siqueira da. Os impactos das políticas de expansão do ensino superior, e os seus reflexos nas relações de trabalho na educação a distância: flexibilização e precarização do trabalho docente. REDD - Revista Espaço de Diálogo e Desconexão, Araraquara, v. 3, n. 1, jul/dez. 2010, p.1-13.

STATA. Statistics Data Analysis. Versao 14.2. Texas (USA): StataCorp, 2015. 